\title{
Truth and MLE - the only way for Eternal Global Peace on Earth
}

\author{
Subhendu Das \\ 24300 Abbeywood Drive, West hills, California 91307, USA \\ Subhendu11das@gmail.com \\ DOI: 10.29322/IJSRP.10.07.2020.p10359 \\ http://dx.doi.org/10.29322/IJSRP.10.07.2020.p10359
}

\begin{abstract}
This article incorporates multidisciplinary contents from mathematics, physics, economics, engineering, history, Vedas, and Bible. All these subjects are also interdependent. This happens because all these subjects are supported by the same money, coming from the same single source, the central bank (CB). Thus global peace, or any phenomenon, cannot be understood from any single subject in isolation. We show that the money is the root cause for everything that happens on our earth.

Unfortunately there is no definition of truth in our modern societies. The principle that - you have your own truth and I have my own truth - is a false notion. And if this was true then Galileo would still be in jail today. If you read carefully then you will find that the following definition of truth is embedded in the pages of both Vedas and Bible: '(1) The laws of nature are the only truths. (2) These laws are created by the objects of nature and their characteristics. (3) Nature always demonstrates all its truths.'
\end{abstract}

You cannot have peace in your mind unless you know this truth. If you observe yourself or anyone carefully, you will find that all of us, knowingly or unknowingly, are always searching for this truth. For the same reason, a society, a nation, and the world will be in eternal peace only if they all know this truth. We show that the soul is the root cause of everything that happens in the universe, which includes the earth.

Such a truth can be implemented and maintained only when the moneyless economy (MLE) is created. MLE is the only economy that is based on the laws of nature. MLE also cannot be maintained without implementing the truth. Thus the truth, peace, and the MLE are synonyms. All problems of our earth, including threats of possible nuclear wars, will be solved almost overnight if you can implement MLE now. Only MLE can bring heaven on earth. If you understand the concept of root cause, then you immediately have the solution to all problems.

Index Terms- Root cause, Peace, Truth, Falsehoods, MLE, Destiny, Eternal Recurrence, Wars.

\section{INTRODUCTION}

To clarify the kind of truth we are talking about, we first present two examples from the observation of nature. These examples were discovered and then presented to the western world by Ian
Stevenson (1918-2007), a Professor of Psychiatry, at the University of Virginia, USA. Some people on the internet called Stevenson as the Galileo of the modern century.

A baby boy was born in a hospital with birthmarks of a bullet wounds on his chest and back. Doctors, nurses, and parents confirmed the observation. When the boy learned to speak around the age of two, then over a period of some time he talked about his past life, which can be summarized in the following way, without the loss of generality. The boy's name was $\mathrm{N}$ in previous life. He died in hospital $\mathrm{H}$ of town $\mathrm{T}$ on date $\mathrm{D}$, due to a gunshot wound on his chest. Over time, the research scholars, news reporters, parents visited the hospital $\mathrm{H}$ and verified everything that the boy had said from the autopsy records of the man named N, who indeed died on the date D [Stevenson 1974].

Such a kid, who remembers his past life, is known as Jatiswar in Sanskrit. On another Jatiswar case, the boy had complications, and the doctors had to perform surgery on the boy to save him. The doctors found the complete straight line bullet path inside the body of the baby, exactly matching the autopsy record of the dead body of the boy's previous life [Pasricha 2005].

The above two examples prove that (1) babies are not naturally grown inside mother's womb. Since there was no brain during the growth period, and yet the baby was manufactured with a bullet path, (2) it was definitely created by the soul and according to the destiny [Das 2013c] of the baby. Thus the examples prove, among other things, (3) the existence of soul, reincarnation, destiny, (4) memory is in the universe and not in our brain [Das 2012c]. It should be pointed out that the blind man example of the Bible falls in this same category of truths.

Both Vedas and Bible say, 'God is spirit.' The spirit is same as soul. And God means creator. Samkhya [SK, 1995], a part of Vedas, explains that statement in details with systematic logic and proof. It says that every object has a soul, and that soul has created that object. The above two examples and the phenomenon is a proof of that theory of creation [Das 2017]. We later point out that the destiny is the highest level law of nature, is precisely predictable, and it contradicts the concept of God as the creator of the universe. If God is the creator of the universe, then God cannot be predictable by humans. Universe is not an object; it is the collection of all objects inside it. 
Samkhya says if you track any cause and effect chain you will always end up with the same root cause, which is called the soul. That means souls are uncaused, therefore they were never created nor can be destroyed, that means they are eternally existent. This soul is the tiniest invisible particle, and is the only object in the universe that has the consciousness property. Since soul is the tiniest particle, it cannot be broken into pieces, and therefore this soul cannot be a part of another bigger soul. The entire universe is filled with such soul particles, just like the entire environment of the earth is filled with oxygen particles [Das 2017].

PROBLEM LIST (PR): Because we do not know such truths and many more related truths, our societies have created many false things which in turn created many problems, which cause pains, and therefore lack of peace. Here is a partial list of some of such Problems (Pr): Wars (local, global, nuclear), discrimination (race, gender, color, nationality, religious, academic), corruption, migration, violence (religious, political, sexual, gun, drug, domestic), family problems (divorce, children, abortion), pollution, poverty (wealth gap, homelessness), medical diseases, financial (unemployment, bankruptcy), lies, cheating, falsehoods (education, democracy), technology issues, natural (wildfire, earthquake, tornado, flood, hurricane), etc.

Any one of these problems will cause lack of peace for any individual. As an example, more than a billion people in our world are under poverty [UNDP 2018] and therefore cannot have peace. If the society cannot protect its members then the society cannot have peace also. We are all interconnected, COVID-19, the pandemic of 2020, proved that very well. Therefore, if any one suffers, then we all suffer.

CONTENTS: Rest of the article contains the following subsections. (1) First we introduce the Definitions of Truth, Peace, and Moneyless Economy (MLE). (2) Then we give an overview of what the New Peaceful World would look like if we implement Truth and MLE. (3) Next we try to see how we ended up in the present state of our world by describing how we created the items in our problem list Pr. (4) To approach the peace we then find that there is a Root Cause for every problem, and it is always the same, money at the level of earth, and then beyond money, the root cause is soul at the level of the universe. (5) This root cause then helps to characterize the problems in a unified way and we discuss Global Destiny and one of its special features called Eternal Recurrence. (6) We show in the Dependence subsection how Truth, Peace, and MLE are dependent on each other. (7) Finally we discuss Global Peace, Myths about Global Peace. (8) We discuss how a Global War for Peace or some other catastrophe that can or must happen to end this civilization. The death of every object in the universe is a law of nature, and our civilization cannot be an exception.

\section{DEFINITIONS}

In this subsection we give definitions of truth, peace, and moneyless economy (MLE). In another subsection we show how they are interdependent.

\section{TRUTH}

Unfortunately there is no definition of truth in our modern society. Most common understanding about the truth is that 'you have your own truth and I have my own truth'. But if that is correct then Galileo would still be in the jail today. If you read Vedas and Bible carefully, and for that matter all books of any religion, you will find the following definition of truth is embedded in their pages and in their theories.

Truth (Tr): (1) Laws of nature are the only truths. (2) These laws are created by the objects of nature and their characteristics. (3) The nature always demonstrates all its truths.

Clearly such truths are unique, universal, and eternal. Unique means one law will not contradict another law, they are independent, and there will be no redundancy. It also means everybody will understand them in the same way. Universal means if a law is valid in USA, then it must be valid in China also. Similarly, if a law is valid on earth it will be valid in any other planet in any galaxy in the universe. And finally, eternal means, if a law was valid million years back, it will be valid now, and will remain valid million years from now. This truth is neither objective nor subjective, because every object has a soul, and the soul is the only particle that has consciousness. Thus such truth (Tr) is the only unifying force at all levels of the universe.

Nature always demonstrates these truths for us to observe, learn, and emancipate. You can see that humans always show us, like in news, if they observe something new for others to learn. The same is true for all objects of nature, because they all have souls, and they want to interact with each other. Therefore, if something is not observed in nature then that cannot be a truth. Fortunately though, all such truths are available on the internet, but you must learn to seek them.

Examples of such laws are: Reincarnation, Destiny, Yogic Power, Eternal Recurrence, etc. Notice that none of them are known to us in modern societies; yet they are all described in all books of all religions, including Bible.

\section{PEACE}

Merriam Webster [Mwb] dictionary says peace is a state of tranquility or quietness of mind. But I can never be in such a state of mind under any one of the above Pr problems. Therefore my society also cannot be in peace. Such a definition does not help anyone to achieve peace and remain in peace. Institute for Economics and Peace, in their positive peace report 2019 document [PPR 2019], says - 'Positive Peace is defined as the attitudes, institutions and structures that create and sustain peaceful societies.' Clearly, peace is defined in terms of peaceful, and which remains undefined. Without a meaningful definition of peace you cannot achieve peace in our world.

We take the following definition of peace from Vedas [SK 1995]. Vedas say (Pc): "you cannot have peace in your mind unless you know the truth'. This definition is quite obvious also, because we are all continuously searching for truth. Bible also has similar statements. For the same reason a society must also 
know the truth to remain in peace, and therefore the nations and the world must also know the truth. Thus the foundations of the world community must be based on truth to enjoy ever lasting peace. The reverse is true also, if there is no peace in the world, then there will be no peace inside the homes.

Thus peace propagates from individual to the universe and vice versa. Thus everything in the universe is simultaneously interconnected. And the root cause, as we learn from the observation of nature, behind this interaction is that we are all souls. Thus the universe is not only physically interconnected but we are also interconnected by the consciousness property of our individual souls. All people must understand and properly verify the truth about souls, only then we can have peace. See the book [Das 2014a] for many proofs for the existence of soul, viewed from three different independent angles - reincarnation, yogic power, and human destiny. Jatiswar example is one such proof which actually demonstrates all three angles simultaneously.

This knowledge or truth about the soul should be the foundation for peace, because this soul is the root cause of all causes in the universe. This is like money, in the sense that money is the root cause of all causes of everything or every activity on earth. If you continue digging deeper after money, you will then find the soul as the next deeper level root cause.

\section{MLE}

In moneyless economy (MLE) there is no money, neither digital nor paper currency, of any type. Under MLE we work free and get everything free. MLE can give us complete freedom and democracy, with any life style you want. MLE is not socialism, because socialism uses money. MLE is not slavery also, because slavery does not give freedom. It is the only natural economy, and therefore it obeys all the laws of nature.

Actually, the idea of MLE is embedded in the present form of CBE (central bank economy), although MLE is a hundred year old concept [Das 2012a]. By giving money you can make anybody do anything you want. Thus CBE is a dictatorship. But MLE will give you a true measure of your success, true value of your wisdom, and your true entrepreneurship for the society. MLE provides the real freedom and democracy, for everybody, rich and poor, equally. The rich can become richer and can even own the whole world under MLE, just like the sun owns the entire solar system. In Ramayan period the king Ravan was the owner of the entire solar system. Note that every planet and the sun also have their own individual souls.

\section{HOW MLE WORKS}

All employees of every employer will have an electronic photo identity card. Eventually all people on earth will have such cards. Everyday all employees will swipe their cards as they enter and exit, to and from their work. This card will have, among other things, a ' $\mathrm{Y}$ ' written electronically, indicating that Yes, the person has worked full time for the previous week.

When the person will go to a grocery store he will buy whatever he needs, as he does now. He will then swipe the card and leave the store. He will similarly go to his apartment or bank, for home rental or mortgage payment, and will swipe his card. There will be no money exchange anywhere. Nobody needs to know what is written in the card, just like we do not know what is written on our present credit cards. There will be a nationwide database for all such cards, just like the credit cards.

Employers will not pay any money to any employee; people will not pay any money for food and shelter. The present economy will thus run exactly the way it is now. Many other details like (1) what happens when a person does not work, (2) what if he wants a vacation, (3) how about the single mother, (4) retirement, (5) travel and hotels, etc., are all discussed in the MLE chapter in the free ebook on Soul Theory [Das 2014a].

\section{NEW PEACEFUL WORLD}

Let us examine how a new peaceful world will look like under Truth and MLE. It appears though that it will be easy to understand that all problems will automatically vanish and heaven will come to earth. But still we illustrate the new world using some small problems and large problems of the present world from the problem list Pr created by the central bank economy (CBE).

POVERTY: Clearly there will be no unemployed persons, because employers will not have to pay any salary. The person can go anywhere freely where he feels he will be qualified and he will be hired. He will not be forced to work on the job that is available. The travel and accommodation to job site of his choice will be free. The person can even implement his own idea and sell it to others, because labor and materials will be free, he will not be required any financial investment. More details can be found in the MLE chapter of the Soul Theory book [Das 2014a].

DIVORCE: Most of the reasons for divorce in a family are due to lack of money. That problem will vanish under MLE. Loss of love between couples will be rare also because both can get all the comforts they need. Every family can get free maid services, car drivers, care givers, kitchen cooks, elderly cares etc. People can even raise their kids in a large joint family and in large houses. A joint family can help to avoid conflicts, and provide philosophical support. However, such joint families cannot be compared with the past joint families, because they were constrained by money.

SEX WORKERS: Many families break apart because of extramarital sexual activities. For such people sex workers will be available as legal jobs. Any job that society needs will be legal and part of the society. Such workers will also live in beautiful houses, well maintained by free gardeners, lawnmowers, maids, painters, drivers, free cars, etc.

HOUSING: Suppose I desire a house in Manhattan, in New York city. Under MLE house price is meaningless. So, all houses will be free. Manhattan is now a center for financial activities. Since 
money is gone under MLE those jobs will be gone too. The city will lose its demands, and people will move out and prefer to stay in houses with gardens and lawns. So there will be many vacant apartments in the sky scrapers, and anyone can occupy them. So very soon you will be able to own the entire Manhattan city, if you so desire.

GUN VIOLENCE: Gun manufacturers will stop their business, because there will be no need for guns for private citizens. All properties will be free for everybody, so nobody will try to steal your wealth. Migration will stop, no one will threaten your job, and so there will be no loss of employment, since employers will not have to pay salary. There will be no racism also. Because people will know the truth that in the previous birth you were a person of the race that you hate now. So the fear of job loss due to racism, migrants, religious affiliation, etc., will vanish.

NUCLEAR WARS: There will be no need for weapons of mass destruction, as no government will threaten any other government for stealing wealth and labor of other nations, since everything will be free. Nations will be ruled by the native people. Foreign workers will be very few and therefore will be highly desired and respected. High level yogis will be available to convert all nuclear materials to say, talcum powder, with no disposal hazards. See the yogic power chapter in the book on Soul Theory at [Das 2014a].

GOVERNMENTS: There will be no need for governments. All industries will be privately owned, there will be no need for providing security to industry owners and also for people or employees. There will be some management of people to see that at least one able bodied-family member is working. However, it is beyond imagination that somebody will not do any work, because the person will be naturally guided by the destiny, and he will not be forced to work on jobs that he does not like.

HOSPITALS: Health care will be provided free also. The medicine companies will not give medicine unnecessarily to keep people sick and unhealthy. Most of the drugs will vanish. Giving injections to babies will automatically stop. Unless somebody is sick drugs will not be given to people on mass scale. All medicines will be free also. Use of placebo will become more dominant.

\section{CREAtion Of Problems}

In this subsection we show how our present societies slowly created all the items in the problem list $\operatorname{Pr}$ over the past thousands of years. We illustrate some problems and their origins.

IGNORANCE: One of the most important problems is the removal of reincarnation from the Bible in around $600 \mathrm{AD}$. However, there are still many verses that may be considered to indicate reincarnation. Like the following - 'Whatever has happened will happen again.' This can mean that since you are here now on earth, therefore you were here before, and you will be on earth again in the future. Reincarnation is the greatest discovery of the mankind but money and money power did not like it for its business and so it was removed. Now all over the world the concept of reincarnation has almost vanished and we have all become ignorant. We now say we have only one life to live, and then heaven or hell [Das 2018].

PROCESS: Another important observable milestone happened when, about 400 years back, Galileo was jailed for observing the nature to discover the truth. Money, money power did not even want to see what he discovered. We call it the Galileo phenomenon. This phenomenon is still happening all over the world, in our industries, governments, and academic institutions. We have different names whistle blowers, traitors, most dangerous man, conspirators, etc.

This made all people scared, and they realized that truth cannot be discovered, because it will reveal the truth about money power. So the entire scientific process was changed. Now, it starts with assumptions, then based on manipulations of the assumptions results are created. But we know that the assumptions are false, therefore all scientific results must be false also. This is so because false can never become true. Thus our entire education system is false now. We point out some false ideas or objects that created large scale problems and falsehoods [Das 2019].

REAL NUMBERS ARE FALSE, because they are not objects of nature, and so you cannot touch, see, or feel a real number. Also, real numbers are considered as points on a straight line. But a straight line does not exist in nature either, because all objects in the universe are continuously moving with respect to each other. Since false can never become true, no matter in how sophisticated ways you manipulate the false (falsehoods), the entire mathematics must be false. Since physics uses mathematics, the physics must be false too. You can then see that our entire education is false. This idea of straight line created infinity which in turn destroyed or corrupted math, physics, and engineering [Das 2012b].

Professor Quigley (1910-1977), a mentor of US President Bill Clinton (1993-2001), said education has three negatives and one of them is - 'never teach the truth [Quigley 1966].' Interestingly, how did Mark Twain and many other western philosophers come to know the same conclusion 'Majority is always in the wrong'? What insights they had? How can you expect peace when our education is false? So, from childhood days we are giving false education. People do not understand now why and how everything is happening and we all remain frustrated.

ASSUMPTIONS AND EXPERIMENTS: Just to convince the reader a simple example, Newton's first law is described. Newton said - 'An object will continue in motion with a constant velocity in a straight line.' Clearly nobody has seen such an object, because Newton assumed 'an isolated environment or in the absence of an unbalanced force', which is not possible, since 
gravity is there everywhere in the universe. Moreover, there is no straight line in the universe. For more examples see [Das 2019]. It should be noted that Einstein also assumed that Newton was correct and used it, as inertial frame, in his special relativity theory; therefore SR must be wrong too [Das 2014b].

No engineering experiment can prove any theory, because all experiments will automatically reject all assumptions of the theories, because engineering is part of nature. And since without the assumptions the theories are all wrong, therefore no experiment has proven any theory. Therefore so far, nobody has verified any theory correctly. Realize that all engineering experiments are correct, they prove or demonstrate a law of nature, but they can never prove any theory based on any assumptions.

ENGINEERING IS CORRECT, because engineering uses objects of nature. However, engineering is unreliable, unsafe, and pollutes the environment. This happens because engineering also uses false mathematics, false science, and false money [Das 2012 b]. Any product that deals with objects of nature is called engineering. Therefore cooking, foods, medical surgery, chemistry, roads, bridges, computers, airplanes, rockets, missiles, etc., are all engineering activities or products.

MONEY IS FALSE ALSO, because money is not an object of nature. Since money is false, money must be free and abundant at its source, which is the central bank (CB). Bloomberg News found that $\mathrm{CB}$ gave secretly more than 10T dollars as bail out money to save the banks during 2008 recessions. At that time US GDP was nearly 14T dollars [Das 2011]. This false money separated, isolated, or discriminated every individual from everything else, that is, from another person, from nature, and therefore from peace. Notice that money is a real number too.

You will never be able to justify the statement - Apple is $\$ 10$. We have assigned money value to every object on earth, and none of them can be justified by any means. You can say that land is $\$ 1$, labor is $\$ 2$, etc., and so total will be $\$ 10$. But the question still remains the same - why the land is $\$ 1$. Similarly, we have assigned to Mr. X \$10/hr and Mr. Y as \$1000/hr, which cannot be justified either.

Since every object and every activity is assigned a money value, you will not find any event, including peace, which is not influenced by money and money power. Therefore the root cause of every problem in Pr can be always traced to money. Thus we are wondering and running around like headless chickens inside a false society created by the false money and the money power.

POVERTY: All activities of the central bank economy (CBE) are designed to create rich people. But you cannot become rich without stealing from others. The major processes for the CBE are private businesses, giving loans, interest charging, creating recessions, etc. Examine the graphs to see how rich is getting richer and poor is getting poorer in [Das 2011].

Let us see how businesses create rich and poor. We make a product at $\$ 5$, then sell it at $\$ 15$, and thus steal $\$ 10$ from every person. The owner of the industry becomes richer and the people become poorer. Thus profiting is same as cheating or stealing. Creating recessions is another way for large scale nationwide theft of wealth by the rich. A Stanford University article says more business means more poverty. See the graphs, created from government data, to examine how interest rate creates unemployment in the article [Das 2011].

Keynes, a well known figure in the economic theories, says -

'By a continuing process of inflation, governments can confiscate, secretly and unobserved, an important part of the wealth of their citizens. By this method they not only confiscate, but they confiscate arbitrarily; and while the process impoverishes many, it actually enriches some. ... The process engages all the hidden forces of economic law on the side of destruction and it does it in a manner which not one man in a million is able to diagnose'.

As we know that governments are also controlled by money coming from the central bank. There are many US presidents and modern economists who also have said the same thing [Das 2011]. Note the phrase 'not one man in a million' is very much similar to what Mark Twain said, 'Majority is always in the wrong' [Twain 1915].

\section{Root CAUSE}

We find that there is a root cause for every object and every activity in the universe. This root cause is same in every case. Therefore this root cause will give us a unified theory to understand the universe. In our technology for example, we have a microprocessor, which can solve all problems from all subjects.

\section{ROOT CAUSE}

For every effect there is a cause [Das 2017]. Since cause and effect are similar we can call them by any name. Thus for that cause there will be another cause. So if we trace any chain of cause and effect, after a finite number of causes, we will end up with a cause which will not have any more causes. This last cause will be same for all chains. This cause is thus uncaused and is called the root cause. This root cause is called the soul. Souls are thus eternally existent. This root cause cannot be eliminated. A soul cannot be killed. All souls together create the global destiny, which therefore is also eternally existent.

Princeton University has demonstrated that even man-made objects like an electronic circuit board has a soul and it can interact with human intentions. A Japanese scientist has shown that water crystals change shape according to our desires. All animals also have souls, we have given butterfly example here. Thus every object including earth, nations, societies, have souls. They all behave in the same unified way as humans do, and according to the same global destiny [Das 2019].

On our earth, a little thinking will show that the root cause is money. Since every object and every activity is assigned a money value, everything that happens is a consequence of money. However, since money is not an object of nature, therefore money is false, so money can be removed, and will not affect anything in our life. We can create moneyless economy 
(MLE). Thus at the level of earth, the root cause is money and at the level of universe the root cause is soul. If you search any cause and effect chain beyond money, of course, you will find the soul.

\section{ROOT CAUSE ANALYSIS}

Root cause is always known, it is soul at the level of the universe, and it is money at the level of the earth. However, for a better understanding of events, we can try to find the cause and effect relationships for any event that we want to investigate. In many cases it is very difficult to know which one is cause and which one is effect. That is, we may not know if A caused B, or B caused A, since cause and effect are similar in nature. It is also possible that there may be a chain of causes $\mathrm{X} 1, \mathrm{X} 2, \mathrm{X} 3$, etc., which eventually caused $\mathrm{A}$. Or even there may be a cause $\mathrm{R}$ which directly caused both A and B. Since there is a root cause, therefore the last option is always the correct one, where $\mathrm{R}$ is soul or $\mathrm{R}$ is money.

AN EXAMPLE: Let us consider the example of eclipse. You can ask why the eclipse happens. Here eclipse is the effect or the event and the answer to your why question will give you the first cause. You can say that the shadow of the earth falls on the moon. You can stop here and feel happy, but then you will not know the root cause. So you can ask again why the shadow covers the moon. The answer will be because the moon rotates around the earth. You can then ask why moon rotates around earth. The answer is - otherwise they will fall on each other. Why they will fall, because of gravity.

But gravity, fall, attract are synonyms. We have seen that humans can levitate, fly, and walk over the ground. Saint Joseph of Cupertino is an example [Grosso 2015]. Thus we do not know the gravity, and therefore we do not know why the eclipse happens. If we do not know the root cause then we will always remain ignorant about all our questions. Such ignorance will keep us unhappy. We will not know that we do not know, but we will be devoid of peace. We will not be able to solve any of our problems in $\operatorname{Pr}$.

ASK NO QUESTIONS: The scientists stopped us at gravity and they did not want to ask any more questions to go beyond that point. It is the money and the money power that stopped them from investigating the Saint and they said levitation is false. So the root cause here is money at the level of earth. But the real answer is soul at the level of the universe. By performing yogic meditation we can learn how to levitate and then know that the real reason is the soul. We do not need wings to fly. If one soul can do something then every soul can do the same thing [Das 2018]. However, we are all guided by our destiny; we cannot do anything we want. We are not our bodies or brains, we are our souls.

Asking a series of questions will lead to the root cause, and the answers will always end with money and then to soul. But we can also stop at any point and feel satisfied with our answers. But then you will never know the truth and become happy. The entire society will remain unhappy and nobody will be in peace. In case of gunshot death, for example, we can get the shooter and jail him. And never try to track the cause and effect chain. Such situations make everybody unhappy.

\section{Global Destiny}

NO FREEWILL: We must have some reasons for any action we take. Therefore our reasons control our actions. So, we cannot have freewill then. Since reasons come before we act, our past reasons control our present action. Thus we cannot have freewill at the present moment. In the same way our past is controlled by another past. Bible also confirms this rational - 'what we sow is what we reap.' Thus no-freewill is a law of nature, and therefore is a Truth, according to Tr. For proofs by observation of nature on no freewill see Pat Norris example [Green 1977].

NO CHOICES: Our mind works sequentially, that is, we cannot think nor do two things simultaneously at any time. We always do only one thing at a time. You can verify it yourself by monitoring your thoughts for few minutes. Thus at any moment we can only have one choice. We analyze the first choice first, and then in the next time slice we analyze our second choice. Therefore, moment by moment, or in every time slice, we always have only one choice. This property of mind is also a law of nature for every object in the universe.

SIMULTANEITY LAW: The most important example of truth $\mathrm{Tr}$ is the destiny law. Look at the operational features inside of any engineering corporation. Everybody is working there like a robot. Nobody has any freewill and any choices while inside there. The corporation has a precise plan for every project, all projects are broken into small tasks, people have been assigned to each one of these tasks, and has a schedule for them. Such a precise plan gives us very good peace at work. When I go tomorrow to my work, I know exactly what I have to do, and there are no worries, no complex politics, no complex thinking, etc.

In the same way, the life of every human being is guided by the global destiny or the global plan of the universe. No-freewill, nochoices are thus two real laws of nature also [Das 2014a]. Our individual destiny is derived from this global destiny of the universe, and similarly the global destiny of the earth, the nations, and the societies, etc., are also linked to this same global destiny of the universe. Destiny is created by the simultaneous interactions of all objects in the universe, just like the way a corporation works [Das 2013a].

PROOF OF DESTINY: Another feature of the destiny law is that the destiny can be predicted exactly with all details, before the events happen, by any high level seer yogi, with the power of third eye. In many cases ordinary people can also predict what will happen to you. Sometimes, someone will come to you and ask you some questions and in response you may predict your own future events correctly. This happens because we are all souls, and all souls know all truths, but we are guided by the destiny. Here is an example of precise destiny prediction.

The well known western palmist Cheiro examined the hands of Mark Twain in 1895, when he was bankrupt and $\$ 94,000$ in debt. Cheiro predicted that he would suddenly become rich in his 68th year (1903). It came true and he signed a contract. Twain wrote - 
'They guarantee me $\$ 25,000$ a year for five years, but they will yield twice as much as that for many a year, if intelligently handled [Twain 1915].' Cheiro was a high level yogi.

Quantum Mechanics (QM) says that you cannot predict anything correctly, because of their Uncertainty Principle (UP). But it has been proven that UP is wrong, it has invalid assumptions; see the details here in [Das 2013b].

Observe that this predictability is also quite natural. We can predict who is doing what at any time inside the corporation, because we know exactly the complete plan. The same will be true for the universe, every soul knows the exact plan, and therefore can predict the future also. This destiny is written in the memory of the universe, and any high level yogi with the power of third eye will be able to see this memory. Since destiny is precisely predictable and cannot be changed, because we neither have freewill nor have choices, God cannot exist and God has no role in our life.

Thus the global concepts, universal truths, laws of nature, destiny, MLE, and peace are all synonyms. Understanding any one of them implies the knowledge of all others. For many proofs of destiny and examples see the book [Das 2014a].

\section{ETERNAL RECURRENCE}

Eternal recurrence is a law of nature which was popularized in the west by the German philosopher Nietzsche [Das 2018]. Another name for it is the common statement - History repeats itself. It is a just beautiful name for periodicity of everything in nature, so common in electrical engineering and software engineering.

Eternal recurrence is a special feature of the destiny law. It says that similar events will happen or repeat periodically. Bible also says 'Whatever has happened will happen again.' The reason behind this law is that every life in the universe is periodic birth, growth, death, dead period, and reincarnate - is one cycle. Eternal recurrences can happen for individuals, businesses, nations, and earth. Roman Empire, Mughal Empire, British Empire have gone through the similar phases. Ramayan War, Mahabharat War, WW2 also have high level similarities. Eternal recurrence cannot be avoided, we can only extend the period, by changing the environment with both Truth and MLE.

Eternal recurrence is a consequence of the principle that says a combination of periodic events will also be periodic. You can draw some periodic waveforms, add them together, and see that a new periodic wave will be generated with different and longer periods. Vedas say that even the entire universe also repeats, and from those graphs you will find it is quite natural too. Thus these periods of events can be 10, 50, 100 years, may be even 1000, million, and billion years long.

MONARCH BUTTERFLIES provide an excellent example of eternal recurrence [Bittel 2017]. They migrate from east coast of Canada to the west coast of Mexico, a 3000 mile journey. They cannot make it in one life, so they die, reincarnate, and continue with the same objective. Scientists have captured a bunch of them, moved them, and released them in different places, but amazingly, they changed their directions to match the original path towards Mexico. This shows, reincarnation is valid for every object in nature, and we continue with the same objectives in the next life, from where it ended in the previous life. Gita also confirms this phenomenon of continuity of objectives in verse [G.5.23]. This is how software engineering is designed also.

Killing any human or regime change will not therefore solve any problem, since that person is a soul, and a soul cannot be killed. That person will reincarnate, will be guided by the destiny, and will continue working from the same state of mind when he died last time. Thus unless we change the environment to truth and MLE, the history will repeat the same falsehoods, and peace will remain unreachable.

\section{DEPENDENCE}

In this subsection we show how Truth, Peace, and MLE are dependent on each other and why they are synonyms. Peace will come only when all problems of Pr will simultaneously vanish for all time and permanently. Thus peace and problems in Pr are related. Truth will be visible when falsehoods are eliminated or understood. Thus truth is related to falsehoods. MLE will eliminate both Pr and falsehoods.

\section{MLE AND PEACE}

MLE will eliminate Pr and therefore will bring peace. We give some examples to show how Pr is eliminated under MLE.

DISCRIMINATION: This is one of the problems in the Pt list. At the present time we have CBE (central bank economy). We see that $\mathrm{CBE}$ cannot give us peace, we do not see any peace anywhere, and we have the problem list Pr. CBE means producing more wealth for the rich and forcing people to consume more for businesses to make more money for the rich. As we have explained before, using such process CBE cannot create rich without making others poor. On the other hand MLE can create rich without any kind of discrimination.

NO DEMOCRACY: CBE controls the governments by its lobbyists who use carrot and stick polices to control elected members of the governments around the world. Public uses the secret ballot but elected officials cannot use secret ballot. This way we can see that there is no democracy for people. CBE has ensured that the nations are controlled, by businesses using its money, and not by people. It is called the dysfunctional democracy. No secret ballot means no democracy. Thus it is the $\mathrm{CB}$ that creates wars, creates weapons of mass destruction, guns, and all the items in the problem list Pr. Again, the root cause for all activities of all nations is the same false money. Only MLE can stop this process and bring lasting peace in the whole world.

LOSS OF QUALITY: Now we do not care for the quality of the products, we care for money only. As an example, we created cars that kill 30,000 people per year in USA alone. We did not try to create safe cars; instead we created more businesses by providing car body insurance, accident health insurance, emergency health care hospitals, car parts and repair businesses, etc. MLE will eliminate all such unsafe engineering and bring peace, and yet manufacture cars. 
Since everybody is forced to work for money, everybody is cheating everybody, including parents, husbands, wives, children, and therefore everybody has become selfish. There is no real love, respect, and sacrifice anywhere in this society. The consequence of such an environment is very severe. I am cheating myself, knowingly and also unknowingly. How can you expect peace in a society based on such deception? Every family is suffering, mentally, physically, and economically. Quality of life has degraded beyond all measures.

LOCAL SOLUTIONS: All local solutions for peace are bound to fail, because they are all controlled by falsehoods, like false money and false education. Our every action is corrupted by false money. Thus stopping a war alone will not solve all problems in $\mathrm{Pr}$, and therefore cannot bring peace. Since MLE uses no money and therefore all Pr problems will vanish and will bring global peace.

Peace should not mean creating a positive environment for $\mathrm{CBE}$ business and economy. CBE business means creating poverty, creating pollution, and destroying planet. You cannot become happy by punishing people to remain poor, and displaced from their homes. Such CBE cannot give us peace.

We are all simultaneously connected and interactive. It is not just physical and economical connection. It is connection among all souls using their consciousness properties. Soul connections are more powerful than everything else. See the yogic power section of [Das 2018]. If anybody suffers then eventually everybody will suffer. Thus MLE is the only solution for eternal global peace. Only MLE can remove poverty, stop pollution, and stop all wars.

\section{TRUTH AND PEACE}

We have listed several problems in Pr, all of which can create lack of peace to anyone and everyone. If you can remove all of them with certainty and permanently, only then we can have eternal peace on earth. But since we are inside the false environment we cannot ensure that any solution will give us permanent removal with certainty. We will see that only truth can give us real solution.

IMPERMANENCE: Our medical industry has the data to show that every disease has been cured by placebo medicine [Rankin 2012]. Medicine companies do not know why placebo works; and therefore they also do not know why medicines work. This shows that the truth is somewhere else: Medicines do not cure diseases; their effect is nothing but placebo effect.

We give injections to people to prevent influenza, but we have seen even after injection people get flu and even die with that disease. Thus there is no certainty that we have a solution, in fact we do not know of any solutions. Thus there is no permanent cure for any kind of diseases. Every now and then we see same problems reappear. These are essentially eternal recurrences in smaller periods. The situation is similar for all cases in the problem list Pr.

GOALLESS: Since we now realize that the entire environment of the present society is false, therefore we cannot have any peace under such a system and its management. We are all frustrated here, we do not know the goals of our lives, and we are all, including doctors, engineers, servicemen, etc., working for somebody else and not for us. As a result we do not enjoy our work; we wait for vacations, holidays, etc, to find peace. We are forced to work; we are incompetent, because our education is false. We are not thinking, not searching for truth. If we search and find truth, we know we will become a victim of the Galileo phenomenon under CBE.

In a false environment everything, including all basic definitions must be false. Therefore the words like truth, peace, wars, love, caring, sacrifice, honesty, sincerity are all false and meaningless. If you know the truth, if you know that the truth is unique, universal, and eternal, only then you will realize the correct meaning of these words. Otherwise, even leaders will also not know the correct strategies for leaderships. Every time the leaders change, the rules will also change. But the laws of nature are unique and universal. Leaders will try different democracies, different economic systems, but the money power will steer everything in its own false direction, which is based on accumulation of wealth. People will not know what they are supposed to do, and the real peace will remain forever illusive.

WE ARE SOULS: If we can tell everybody that we are souls and not our physical bodies then that truth alone can make a significant impact on our understanding of all truths. Soul is the root cause of all causes at the level of the universe. People must verify and understand the concept of soul. The society will then automatically move towards lasting peace. Such fundamental truth about soul is missing in our life at present time on our earth and so we do not have peace.

\section{TRUTH AND MLE}

$M L E$ can eliminate falsehoods or make us understand the falsehoods. Once falsehoods are understood truths will automatically appear again.

Money is false, so money can be manipulated secretly and also openly to control anything and everything, including the truth. We have seen that there is no truth in the modern society under CBE. Truth and money are contradictory forces, since money represents false. Whatever we create using false money, must be false, because false can never become true. Thus without MLE truth cannot be seen and therefore peace cannot be achieved either.

The reverse is also true. MLE also cannot be achieved or maintained without a thorough understanding of truth. It is not necessary to give money to make somebody work. Everybody needs food and shelter, so people will work free to get them free. They will work according to their interests. We do not have to force them to work in areas that they do not need or like. They will work for truth, to discover truth that they enjoy. Somebody may want to sing all day, find new meaning of life through music, spread that information, and people will also enjoy. That will be his work. Thus MLE will work only when people will be allowed to work for truth.

Therefore MLE cannot be achieved inside a false environment. Thus a completely different education system must be used to train people to observe the nature. We are part of nature and we are immersed inside the laws of nature. Galileo was the only person in modern times, out of two billion people on earth, who 
saw the truth. A truth seeker must have the characteristics of Galileo: sincere, dedicated, and persistent in the pursuit of truth. Only MLE can support such characteristics.

\section{GlobAl PEACE}

ALLOW TRUTHS: People must know the truths, the reasons behind all problems, the root cause, etc. Only the truth can establish the permanent global peace. Keeping truths hidden cannot bring permanent peace anywhere in the world. You never know - how much power a human soul has, and what is stored in the global destiny. Given equal opportunity anyone may come up to the task of implementing global peace by implementing MLE. Note that without MLE there will be no peace. Knowledge of such truths can trigger a new generation of souls and can create a new era for the global peace in near future.

PAST FAILURES: Local solutions cannot bring global peace. A piecemeal approach cannot even make any incremental peace, because we are living inside a false environment, and false can never become true. Such solutions will also never be sustainable. Great honors were given to many people in countries around the world. But do we see peace in those countries after 30-40-50 years? Do we have peace in South Africa, Israel, and Palestine? Things must be tuned with the laws of nature. Wars and Military are not the only things that destroy peace; creation of some of the problems in the list Pr is a much bigger way for slow and painful death of humanity.

LESSONS LEARNED: Formation of EU was one of the major achievements towards the global peace. But EU management, particularly by ECB, did not pay attention to create the environment for preventing the reemergence of problems in $\mathrm{Pr}$. Thus ECB did not know the truth about eternal recurrence, and therefore economic objectives did not mature. Note that, just like the CEO is responsible for every activity of a corporation, similarly the $\mathrm{CB}$ is also responsible for every activity of the entire world economy.

Thus along with EU, which is a first step towards the one world order, we must also implement truths, or at least let the people know about the truths defined by Tr. Only then global peace can be achieved. Otherwise similar problems will come up, due to eternal recurrence, in similar forms in every few decades, and centuries, and peace will never happen. Loss of peace will appear in different forms, not necessarily as physical wars but as pollution, economic wars inside a country or between nations, spreading of diseases, natural disasters, etc. Therefore regime changes, as was done in EU, alone cannot bring peace. The ground work for MLE, which is truth, must be created also. Eternal recurrence should be considered as a major lesson from the events within the last hundred years. A reincarnated soul will not be able to perform the same activity if the CBE changes to MLE or truth is implemented globally.

\section{ELECTION FOR MLE}

MLE EDUCATION: Without a thorough understanding of the truths Tr, peace cannot happen. Peace has a practical implication also, MLE must be implemented. MLE is the only natural economy [Das 2012a]. MLE represents the truth. Therefore
Peace, Truth and MLE are synonyms. Implementing MLE is the major requirement for creating a permanent global peace on earth. Propagating the truths about life and the universe is a necessity for understanding and sustenance of MLE.

The MLE concept should be debated and understood worldwide at various levels. It is necessary to propagate the idea to convince that MLE cannot harm anyone, including the riches. Universities should offer courses on the subject. MLE is the only real and natural economy, which obeys the laws of nature. Just like nature cannot hurt anyone, in the same way MLE also cannot hurt anyone. Just like nature allows any soul to become as powerful as it wants, like a galaxy, or the sun, similarly MLE also gives you equal opportunity to take your goals for the society to any heights.

GRASSROOTS: Organizations should be created to promote people to stand for election at local, state, and national levels. The mission of the candidates will be to implement the MLE once elected, in small steps, or on overnight. Modern technology can help to make the transition smoothly and peacefully.

MLE can be implemented secretly if desired, without even people knowing it. Only way the people will see the results is that there will be plenty of jobs, wherever you want to work, because employers will not have to pay for the salary. You can also start your own job easily, because people and resources will be free. Other methods are described in the MLE chapter of [Das 2018].

Within five years the power of truths will automatically stabilize the MLE process successfully. If required, all present day solutions to all problems of the CBE can be modified, extended, and implemented for MLE, with a little thought. Our global history for last 300 years provides many examples of efforts in vain. It is time that we follow the natural laws.

\section{Myths About PeACE}

If we do not have a meaningful definition of peace then we cannot create peace. Many institutions and prominent people say - you will get peace if you introduce education, remove corruptions, create democracy, implement equality, create action plans, stop wars, etc.

But we have shown that education is false and therefore this education cannot give you peace. Corruption cannot be eliminated unless we remove money, because money itself is false, and therefore is the source of all corruptions. We do not want equality, we want equal opportunity. Equality is discrimination in disguise, because no two objects in nature are equal. We also know that there is no democracy in the world, because there is no secret ballot in any capitol of any nation. Public ballot for elected officials invalidates the concept of secret ballot for people. Our elected representatives in the capitol are controlled by the $\mathrm{CB}$ using the carrot and stick policy through their lobbyists. No action plan for peace can work in the false environment; money will destroy it eventually, the effort will be wasted. Wars are inevitable in a false environment, because falsehoods will create suppressor and suppressed among nations. 
There is no peace in the world now. In USA, California is burning with wild fire; and there is severe flood, tornado, hurricane, earth quakes, gun violence, large scale incarcerations, drug addiction, etc., in other parts of USA. In EU we see instability in Portugal, Spain, France, mismanagement due to Brexit, Grexit, migration problems, racism, etc. There is wild fire and earth quake in Australia, and in many places we see volcano and mud slides, rise in ocean water level, etc. It is not just the war that is creating absence of peace; earth itself is not in peace. Over and above we have added global pandemic due to corona virus now.

No local solution or prevention of wars can bring global peace, not even local peace, because the world is integrated. We must establish the truth and implement the MLE to bring peace; no other way can give us global peace. If we do not take proper action then the earth will take action, environment will be polluted, and we all will be destroyed.

\section{Global War For Peace}

Death and reincarnation is a periodic law of nature. Even the entire universe dies and reincarnates as a result of this periodicity. So the present society will also eventually die just like it happened for all past empires and societies. But by implementing truth and MLE we can bring peace and extend life. We present some history of wins, losses, and the inevitable events.

VEDIC WARS: Vedas describe two major wars, one in Ramayan period and the other one in Mahabharat period. There was probably a million year gap between them. In both wars all powerful kings were killed, millions of people were killed, and billions were rescued. Each war was led by one very high level seer yogi, and a new long peaceful period was established, based on Truth. The book [Das 2014a] describes some high level and detailed level similarities between the two wars. They justify the Bible statement 'There is nothing new under the sun'.

MODERN WARS: Professor Carroll Quigley, mentor of the US President Bill Clinton, wrote in his classic book Tragedy and Hope [Quigley 1966], that 'the financial system has a goal to implement a unified system all over the world'. Along that line, during the WW1, it was planned and claimed that this war would be the war to end all wars. But that goal was not achieved. WW2 was pretty successful in creating EU, and virtually eliminated wars in major parts of the world. Many kings were killed, millions of people were killed, and billions of people were rescued from the European colonies. EU was the first successful local approach for One World Order. But unlike the Vedic wars, the fundamentals were not changed, the truth $\operatorname{Tr}$ was not established.

Then the wars were started in the remaining parts of the world. Again many kings were removed or killed; CB was established in those countries. Wars are still continuing but the mission has been accomplished - unified financial system (CBE) is in place in those countries. But this time also truth was ignored. As a result the nationalism, dismantling of global approach, antimigration, local views, border walls, etc., have resurfaced in the world again, including in the EU, which WW2 claimed to have solved. Thus eternal recurrence happened, history was repeated again, but there was no long peaceful period. Unless truth $\operatorname{Tr}$ is established peace will never come.

TWO NATIONS: All but two nations do not have western style central bank: North Korea and Iran. As a result war drums are beating against them. But if we can implement MLE then these upcoming wars can be avoided, and they will also automatically implement MLE. Otherwise the war will be inevitable. This war will most likely be a nuclear war and many people will die but still peace will not come, because all the problems of Pr will still be there. Although deaths do not really matter, because we are all souls, souls cannot be killed, we will all reincarnate, and this will still be a part of the global destiny. But in every life people will continue to suffer with no peace in sight.

THERE ARE INDIVIDUALS among us who have succeeded in achieving peace. They have good health without visiting any doctor. There are people who die peacefully without suffering. There are yogis among us who can heal other people. There are people who get cured by placebo medicine. Even placebo surgery also works for many. All of them knew the truths and experienced them in their lives also. We must increase the population of such people by spreading the universal truths to everybody to bring global and ever lasting peace.

GREAT FAILURES: On the other hand, because of falsehoods, we see great failures in implementing peace at larger scales. Most notable is Gandhi's failure to free India from the British rule even after a long sustained non-violent opposition for decades. Similar is the failure of the worldwide occupymovements of 2011 that started around the Wall Street as a grassroots phenomenon. Failure of war on poverty movement is another major example. Victor Hugo described poverty 150 years back, in his book Les Miserables, but that poverty is still there in the same way. It has now spread all over the world, and the wealth gap is still increasing. We can give trillion dollar tax cut for the rich, but we do not want to give trillion dollars to eliminate poverty, even though money is free.

SUPPRESSOR AND THE SUPPRESSED: The fact is that - never in the history of the world, a suppressed community was successful in their liberation from their suppressors, without an active support from someone in the suppressor community. Freedom of African-American slaves, freedom from South African apartheid, etc., are such examples of support from the suppressors. But these results are still not permanent solutions for peace, because falsehoods remained. We have only transformed one problem to another. This suppressor and suppressed concept is valid even between nations, between businesses, inside a business, inside governments, and even inside homes.

TRUTH IS A MUST: The above examples illustrate the point that under falsehoods no peace efforts, grassroots movements, unified financial system $(\mathrm{CBE})$, or wars can succeed. We must spread the truth to the level of societies and nations. To know the truths clearly, we must also know the falsehoods. We have shown that everything in our world is false now. Most of our teachers do not know the truths; therefore the students and the people cannot 
know the truths also. In such environment only those who seek the truth can know the truth. All truths are known, and are there on the internet. Everybody will know them only when the environment is corrected.

THE RICH, it seems, really do not know the fundamental truth that - you cannot become rich without making me poor. As mentioned before, there is no win-win situation, win-lose is a law of nature. Thus under the CBE (central bank economy), all economic activities are designed to rob wealth from the people [Das 2014a]. But under MLE the rich can remain rich, become even richer, but equal opportunity and democracy will be available for everybody. Once understood, the rich can play a major role in spreading the truths.

BIGGEST WAR: Milton Friedman, a Nobel laureate in economics, said [Friedman 2006] - 'How to get rid of the CB is an unsolved problem of the day'. And he is very correct. Therefore one greatest hope for peace is that one day the $\mathrm{CB}$ will switch from CBE to MLE on its own as a part of its own destiny. If we cannot switch to MLE peacefully, then another high level yogi will have to take birth, just the way Vedas have mentioned, and also as a consequence of eternal recurrence, to create another major world war, far bigger than what we have seen before, to produce One World Order, establish the truth Tr, implement MLE, and emancipate billions of people who are suffering from the problems in Pr.

We should realize, as mentioned, that regime change cannot solve the problems, because a soul cannot be killed. We will reincarnate with our past characteristics at the time of death. Eternal recurrence will happen, to destroy the peace, because we did not eliminate the falsehoods. Truth and MLE must be implemented together for eternal peace to happen.

The next global war, if it becomes required, would likely be devastating. And until then the present status will continue, pollution will grow, poverty will increase, racism will be on the rise, incarceration in jails will fill up every nation, equal opportunity will be prevented, and increasing the wealth gap will severely destroy our population. That is, each item in Pr will remain and become only more severe.

\section{CONCLUSIONS}

No human being, society, or nation is isolated on our earth and from the universe. They are all interconnected by two means: (1) by using the consciousness property of their individual souls at the level of universe and (2) by the money and money power originating from the same single source, the central bank (CB), at the level of earth.

Therefore no isolated local solution for peace will ever work. Valiant efforts were given by many political leaders, institutions, and individuals for decades, but the peace still remained an illusion only. This article presented an unified approach based on the root cause and the laws of nature that can give global peace all at once and simultaneously all over our planet. This concept should be understood, propagated, and systematically pursued.
Eventually, one day this effort will bring the desired result. The result can be achieved immediately, if you can implement it now.

As long as money is there peace cannot happen, because falsehoods will remain. Thus MLE must be implemented for global and eternal peace. But MLE cannot be implemented without implementing the truth. Thus truth is required for MLE which in turn is required for eternal global peace.

\section{DECLARATIONS}

\section{ABBREVIATIONS}

MLE: Moneyless Economy

CB: Central Bank

CBE: Central Bank Economy

ECB: European Central Bank

WW: World War

\section{ACKNOWLEDGMENT}

There was an email forum which helped this author in many different ways in his research. Without their active help this project could not have reached at its present level. Almost all of the members had $\mathrm{PhD}$ degrees in their respective fields. They were author's colleagues, friends, and relatives. They worked in various corporations and universities in US and abroad. All of them were significantly better than this author. This author remains deeply indebted to them. The group became inactive once the major parts of the project were completed.

\section{REFERENCES}

1. Bittel, J. (2017). Monarch Butterflies Migrate 3,000 Miles-Here's How. Published October 17, 2017.

2. Das, S. (2011). Federal Reserve's Plan to Transfer Wealth. Conference Proceedings NBEA, Philadelphia.

3. Das, S. (2012a). Moneyless economy, The business review, Cambridge, Vol. 20, No. 1, Summer, 2012, pp. 17-25. Awarded Best Paper.

4. Das, S. (2012b). Rethinking Embedded System Design. Int J Engg. Vol 6. Issue 2.

5. Das, S. (2013a). A scientific theory of destiny, Global Journal of Science Frontier Research, Mathematics and Decision Sciences, Volume 13 Issue 8 Version 1.0 Year 2013.

6. Das, S. (2013b). Assumptions in Quantum Mechanics. International Journal of Theoretical and Mathematical Physics, 3(2): 53-68 DOI 10.5923/j.ijtmp.20130302.02. (2013)

7. Das, S. (2014a). Soul Theory website. https://theoryofsouls.wordpress.com/, 2014. Free ebook on the internet.

8. Das, S. (2014b). Michelson-Morley experiment proves light speed is not constant. Physics Essays, 27-1.

9. Das, S. (2017). Vedic theory of everything. International journal of scientific \& technology research, Vol 6, Issue 1, January 2017.

10. Das, S. (2018). Soul Theory, An ebook, pdf. Free on the internet, https://www.academia.edu/8587620/Soul Theory A Book

11. Das, S. (2019). A comparison of modern science with Vedic science, Research and science today, No 1(17).

12. Friedman, M. (2006). -Abolish the Fed. May, 2006, http://www.youtube.com/watch?v=JL3FT0O4kYg\&feature=related

13. Green, E. and Green, A. (1977). Beyond Biofeedback. USA: Merloyd Lawrence Book, 368 pages, 1977.

14. Grosso, M. (2015). The man who could fly: St. Joseph of Cupertino. History's Most Outstanding Case of Levitation, Witnessed by Multitudes, Expert Discusses, 2015. https://www.theepochtimes.com/historysmost- 
outstanding-case-of-levitation-witnessed-by-multitudes-expertdiscusses 1413136.html

15. MWb, https://www.merriam-webster.com/dictionary/peace

16. Pasricha, S K., Keil, J., Tucker J., and Stevenson, I. (2005). Some Bodily Malformations Attributed to Previous Lives. Journal of Scientific Exploration, Vol. 19, No. 3, pp. 359-383 (2005).

17. PPR. (2019). Institute for Economics \& Peace. Positive Peace Report 2019: Analysing the Factors that Sustain Peace, Sydney, October 2019. Available from: http://visionofhumanity.org/reports.

18. Quigley C, Tragedy and hope, A history of the world in our time, 1367 Pages, Macmillan company, NY, 1966, http://www.carrollquigley.net/pdf/Tragedy and Hope.pdf

19. Rankin, L. MD. (2012). - Is there scientific proof we can heal ourselves? TEDxAmericanRiviera, December 2012. https://www.youtube.com/watch?v=LWQfe_fNbs

20. SK. (1995). Samkhya Karika. of Isvara Krsna, with the Tattva Kaumudi, of Sri Vacaspati Misra, English translation by Swami Virupakshananda, Sri Ramakrishna Math, Mylapore, Madras, India, 1995.

21. Stevenson, I. (1974). Twenty cases suggestive of reincarnation. Charlottesville: Univ. press of Virginia, Second Edition, 1974.

22. Twain, Mark. (1915). Notebook, The Prophecy, page 381, pdf version, free on the internet

23. UNDP. (2018). global Multidimensional Poverty Index (MPI). published by the United Nations Development Programme (UNDP) and the Oxford Poverty and Human Development Initiative (OPHI), https://feature.undp.org/multidimensional-poverty/

\section{AUTHOR}

Subhendu Das, received his $\mathrm{PhD}$ in Electrical Engineering from Indian Institute of Technology, Kanpur, India. He had the opportunity to teach as a faculty member in the electrical engineering department of Jadavpur University, in Kolkata, India, and also in the operations management group of the Indian Institute of Management, Joka, Kolkata, India. He has hands-on experience in the microprocessor based embedded engineering systems at various capacities in many commercial, military, and medical industries in USA. In USA he taught as adjunct faculty in the electrical and computer engineering departments of California State University at Northridge and Pomona campuses. He has published one book, many articles in the multidisciplinary fields, and has two US patents. He can also be reached at the alternate email: subhendu.das@excite.com. 